\title{
TRAINING IN INNOVATIVE TECHNOLOGIES FOR CLOSE-RANGE SENSING IN ALPINE TERRAIN
}

\author{
M. Rutzinger ${ }^{1,2}$, M. Bremer ${ }^{1,2}$, B. Höfle ${ }^{3,4}$, M. Hämmerle ${ }^{3,11}$, R., Lindenbergh ${ }^{5}$, S. Oude Elberink ${ }^{6}$, F. Pirotti ${ }^{7}$, M. Scaioni ${ }^{8,9}$, D. \\ Wujanz ${ }^{10}$, T. Zieher ${ }^{1,2}$ \\ ${ }^{1}$ Institute for Interdisciplinary Mountain Research, Austrian Academy of Sciences, Austria - martin.rutzinger, magnus.bremer, \\ thomas.zieher@oeaw.ac.at \\ ${ }^{2}$ Institute of Geography, University of Innsbruck, Austria - martin.rutzinger, magnus.bremer, thomas.zieher@uibk.ac.at \\ ${ }^{3}$ GIScience, Institute of Geography, Heidelberg University, Germany - hoefle@uni-heidelberg.de \\ ${ }^{4}$ Heidelberg Center for the Environment (HCE), Heidelberg University, Germany \\ ${ }^{5}$ Dept. of Geoscience \& Remote Sensing, Delft University of Technology, The Netherlands - r.c.lindenbergh@tudelft.nl \\ ${ }^{6}$ ITC - Faculty of Geo-Information Sciences and Earth Observation, University of Twente, The Netherlands - \\ s.j.oudeelberink@utwente.nl \\ ${ }^{7}$ Interdepartmental Research Center of Geomatics (CIRGEO), University of Padova - francesco.pirotti@unipd.it \\ ${ }^{8}$ Department of Architecture, Build Environment and Construction Engineering, Politecnico di Milano, Italy - \\ marco.scaioni@polimi.it \\ ${ }^{9}$ College of Surveying and Geo-Informatics, Tongji University, Shanghai, P.R. China - marco@tongji.edu.cn \\ ${ }^{10}$ Institute of Geodesy and Geoinformation Science, Technische Universität Berlin, Germany - daniel.wujanz@tu-berlin.de \\ ${ }^{11}$ Research Group for Earth Observation, Department of Geography, Heidelberg University of Education, Germany - \\ haemmerle@ph-heidelberg.de
}

\section{Commission II, WG II/10}

KEY WORDS: knowledge transfer, $\mathrm{PhD}$ training, summer school, natural hazards, vegetation mapping, glaciology, terrestrial laser scanning, close-range photogrammetry, thermography, education, multi-temporal $3 \mathrm{D}$ point cloud analysis

\begin{abstract}
:
The $2^{\text {nd }}$ international summer school "Close-range sensing techniques in Alpine terrain" was held in July 2017 in Obergurgl, Austria. Participants were trained in selected close-range sensing methods, such as photogrammetry, laser scanning and thermography. The program included keynotes, lectures and hands-on assignments combining field project planning, data acquisition, processing, quality assessment and interpretation. Close-range sensing was applied for different research questions of environmental monitoring in high mountain environments, such as geomorphologic process quantification, natural hazard management and vegetation mapping. The participants completed an online questionnaire evaluating the summer school, its content and organisation, which helps to improve future summer schools.
\end{abstract}

\section{INTRODUCTION}

Mapping in mountain environments is a challenging task as areas of interests are often difficult to access. In addition, earth surface processes in Alpine landscapes pose challenges because they are driven by various dynamics, such as continuously evolving processes and spontaneously triggered events. Close-range sensing techniques offer innovative ways of mapping, monitoring and analysing mountainous landscapes and geomorphological processes that occur frequently and on a detailed spatial scale. Data collected by close-range sensing are useful for analysing mountain landscape phenomena and can serve as ground truth, calibration and validation datasets in satellite remote sensing. The dissemination of science is a crucial aspect of research, and dissemination through training is particularly important because it shares knowledge acquired through research to a wider public of potential scientists and professionals. Part of the mission of the International Society of Photogrammetry and Remote Sensing (ISPRS) is education and outreach, which is laid down in its Commission V. Generally, ISPRS members support this vision in a multitude of working groups and institutions. One of the ways that allows ISPRS members to support this vision is to organize educational events, such as the "Innsbruck Summer School of Alpine Research" on "Close-range Sensing Techniques in Alpine terrain" presented in this paper. This event hosts full five days of theoretical and practical training in a location which provides study sites for several earth surface phenomena related to natural hazards, vegetation mapping, permafrost and glaciology in mountain terrain. In this paper, we report on training structure and activities. Improvements vis-à-vis the past edition (Rutzinger et al., 2016) are highlighted and discussed.

\section{MATERIALS AND METHODS}

\subsection{Study area}

The summer school was held at the Obergurgl University Centre (UCO) in Obergurgl (Austria) which is situated in a high mountain environment (Figure 1). The site offers several study objects of interest for parameters related to environmental monitoring. Within a radius of a few kilometres, several diverse study cases in Alpine environment are present, including ice and rock glaciers, permafrost, forest and treelines, lakes, river erosion, landslides and rock fall. The UCO and the related Alpine Research Centre Obergurgl (ARO) of the University of Innsbruck have a long research tradition from a natural science perspective in this region (cf. ARO, 2018). 
The summer school is scheduled for one whole week as a combined event of keynotes, lectures and practical group assignments in both field and lab. The topics worked on during the summer school serve to elaborate a specific technical aspect of sensors, optimum acquisition set-ups, automated data processing and analysis and thematic applications of mountain research into natural hazards, forestry and vegetation and geomorphology.

The Organizing Committee consists of eight people from Austria, Germany, The Netherlands and Italy. Keynote speakers are renowned for their expertise in earth observation, laser scanning, photogrammetry and natural hazard management. Support staff helped with the documentation of the summer school, the organization of assignments and sensor demonstrations.

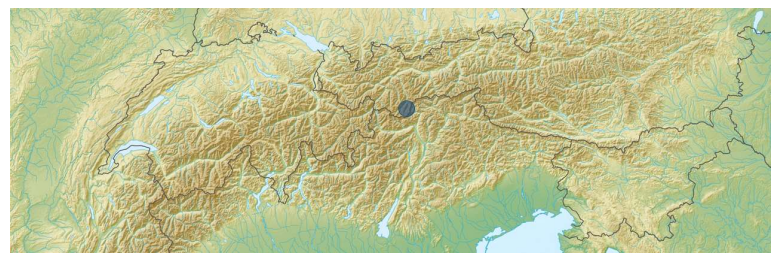

Figure 1. Location of the summer school venue Obergurgl (Austria) in the Alpine context (modified Alps location map by Map Lab CC BY 3.0)

\subsection{Candidate selection}

An international call for participation was advertised through several networks and information channels, both academic and non-academic. The goal was to select a maximum of 40 participants in by a two-stage procedure. Interested individuals applied by sending their CV and a motivation letter. Then the most eligible participants were selected, with priority given to $\mathrm{PhD}$ students and early Post-Docs. Unfortunately not all applications could be accepted for participation. Initial selection was carried out independently by three members of the Organising Committee. The results were compared, candidates ranked and finally selected. Ranking allowed setting a priority in case of last-minute cancellations. This year's summer school with 38 participants from 15 countries was even more international than the first one. A travel grant could be provided for three of the participants.

\subsection{Keynotes}

Keynotes at the summer school give fundamental insights into state-of-the-art developments or a detailed overview of scientific work in selected environmental monitoring. This year's keynotes were: Thomas Geist (Austrian Research Promotion Agency) on The Copernicus Programme and other European Earth Observation activities from space, (cf. Butler, 2014). He also reported on future Earth Explorers Missions which will aid earth monitoring, particularly for the atmospheric, geo- and biosciences. Hans-Gerd Maas (TU Dresden, Germany) talked about Terrestrial photogrammetry techniques for glacier monitoring at high spatial and temporal resolution (cf. Schwalbe et al., 2016). Norbert Pfeifer (TU Wien, Austria), in his keynote on Laser scanning fundamentals and challenges for mountain research - from active sensors to point clouds, introduced the technical aspects of 3D data acquisition by laser scanning and its analytic potential (cf. Kraus, 2007). Cees van Westen (University of Twente, The Netherlands) talked about Natural hazard processes in mountainous environments - assessing hazards and risk, giving an overview on research in natural hazard processes with examples from mountain areas in China (cf. van Westen, 2018). Roderik Lindenbergh (TU Delft, The Netherlands) demonstrated applications of Sentinel data processing for snowand hydrology-related research in his talk on Monitoring high mountain Asia by remote sensing - Sentinel 2 and related data (cf. Phan et al., 2017).

\subsection{Lectures}

The summer school started with a lecture by Martin Rutzinger on Applications of close-range sensing in mountain research, which introduced all participants to the study area of Alpine research in Ötztal (Tyrol, Austria) and the Obergurgl University Centre and offered an overview of research topics conducted in mountain research with close-range sensing monitoring approaches (e.g. Bremer et al., 2017; Mayr et al., 2017; Niederheiser et al., 2018). The vital importance of registration in the context of deformation monitoring and related issues were subject of Daniel Wujanz' talk entitled Terrestrial laser scanning for geomorphometry (cf. Wujanz et al., 2016). Detecting geometry changes using point cloud data by Roderik Lindenbergh gave an overview of methodology to detect and parameterize change in surfaces sampled by repeated laser scan data, including methods that avoid registration, (cf. Shen et al., 2016) and with an outlook to permanent laser scanning as will also be performed at the Hintereisferner about $\sim 20 \mathrm{~km}$ from Obergurgl. The talk Point cloud processing and segmentation by Sander Oude Elberink discussed the general steps for retrieving object information from a point cloud: determining point-based features, followed by segmentation and classification based on information on how objects appear in the point cloud and in reality (cf. Oude Elberink $\&$ Kemboi, 2014). Since the wide spread of Structure-fromMotion (SfM) photogrammetry in geosciences (Eltner et al., 2016), the lecture on Fundamentals in photogrammetry offered by Marco Scaioni was aimed at supplying basic information and background on this relevant technique (cf. Scaioni et al., 2015).

\subsection{Training rationale}

The training rationale rests on three pillars: lectures by senior researchers, field surveys and practical assignments. Assignments provide important support in the training process, as has been demonstrated in the first Summer School 2015 and in other cases (Scaioni et al., 2017). First, because they help students to understand how theoretical background may followup into practice. Secondly, because they stimulate students in an active-learning fashion. Indeed, assignments do not merely consist of standard procedures to be applied, but involve the search for optimal solutions and may require facing problems that come up when dealing with real data sets. Therefore time was set aside to work on assignments. Table 1 lists the topics of the assignments. Participants could select three assignments ordered by preference and groups were formed depending on first choice and the other two most favoured assignments. This combination also helps to identify best-liked topics for future summer school editions (see scholar feedback in Sect 3.2). Each assignment was led by a tutor, who organized the relevant field surveys and other activities.

The participants were expected to bring a poster representing their latest research. This helps to introduce researchers to each other to foster discussion and share experiences. The daily schedule was divided between lectures, demonstrations (e.g. surveying by unmanned aerial vehicles (UAVs) or mobile mapping sensors), field surveys and work on the assignment with data obtained from the field survey. 


\section{Assignment}

1 Rock face characterization: automatic detection of fractures, slabs, cracks and iron equipment from terrestrial laser scanning point clouds

2 Cool trees? - Understanding thermal properties of high vegetation in different scales by thermography

3 3D Geomorphologic feature and deformation analysis in point clouds - examining geomorphologic features and quantifying surface deformations on an active rock glacier via the analysis of multi-temporal 3D point clouds acquired with terrestrial LiDAR

4 Watching grass grow and hills slide: terrestrial laser scanningbased deformation monitoring

5 Classification and validation of 3D point clouds with a data-rich set of descriptors

6 How the mountain river modifies the ground: A UAV application project

7 Find the differences, the geo-version - Change detection in multi-epoch point clouds in Alpine areas -or- change detection between point clouds from terrestrial imagery and laser scanner data

Table 1. Assignment topics
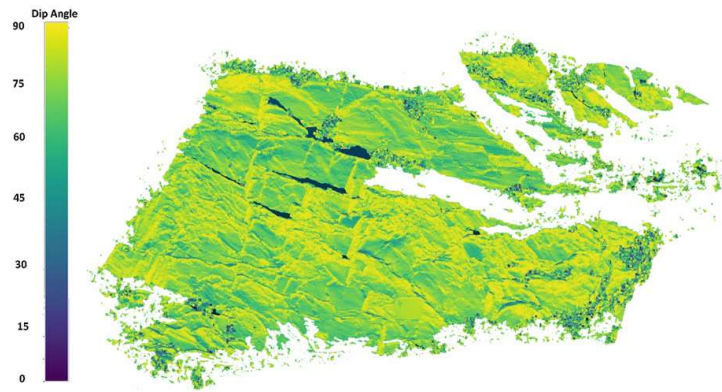

Figure 2: Local dip angles or inclinations of the rock face considered in Assignment 1. A dip angle of 90 degrees indicates a locally vertical rock

Assignment 1: Rock face characterization: automatic detection of fractures, slabs, cracks and iron equipment from terrestrial laser scanning point clouds. Rock faces are prominent landscape elements where geological formations can be examined directly. Generally their characteristics are studied in terms of fractures, orientation and stratification by geologists. Outcrops are often exploited for excavation purposes and may be hazardous to people and traffic, notably when rock is loose and brittle. Finally, outcrops are often used for recreational purposes by rock climbers. For all these target groups, rock geometry is essential. Therefore the goal of this assignment was to sample a rock face by a dense point cloud and to use automatized methods to extract rock face geometry from the resulting dataset. Main objectives of this assignment were data acquisition planning at a given site, identifying parameters that characterize the geometry of a rock face, identifying methodology to extract these parameters in an automated way, ad hoc discussion and validation of the results, and reporting on workflow and results (see Fig. 2).

2.5.1 Assignment 2: Cool trees? - Understanding thermal properties of high vegetation in different scales by thermography. Vegetation is supposed to have a cooling effect to the earth surface. However, the distribution and change of temperature over time differs depending on where on the tree temperature is measured. The goal of Assignment 2 was to investigate how temperature is distributed in high vegetation and how it changes over time. Reference measurements were conducted using ibuttons ${ }^{\circledR}$ and thermal time series of single or a group of trees using the Infratech VarioCam ${ }^{\circledR}$ high resolution research camera (Fig. 3).

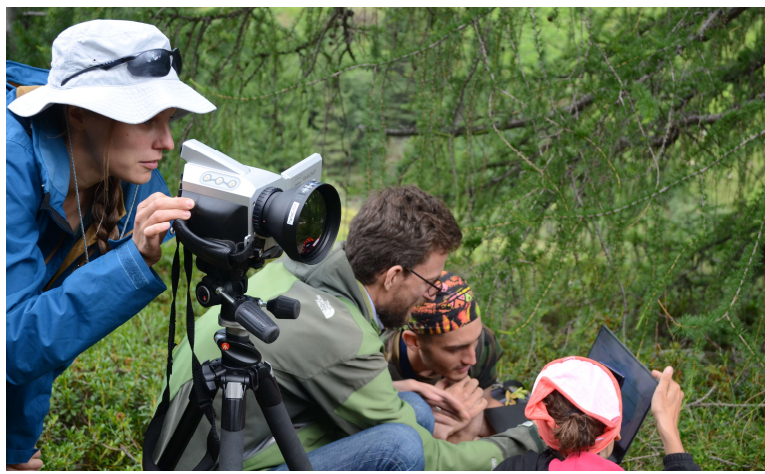

Figure 3. Thermography acquisition in the field

Assignment 3: $3 D$ Geomorphologic feature and deformation analysis in point clouds - examining geomorphologic features and quantifying surface deformations on an active rock glacier via the analysis of multi-temporal $3 D$ point clouds acquired with terrestrial LiDAR. This assignment provided an insight into the acquisition and analysis of multi-temporal 3D point clouds with a focus on Alpine geomorphology (Fey \& Wichmann, 2017; Micheletti et al., 2017; Wujanz et al., 2017). The participants learned about the main point cloud processing steps, which include data acquisition planning, actual field work, point cloud pre-processing and analysis methods, contextual interpretation of derived results.

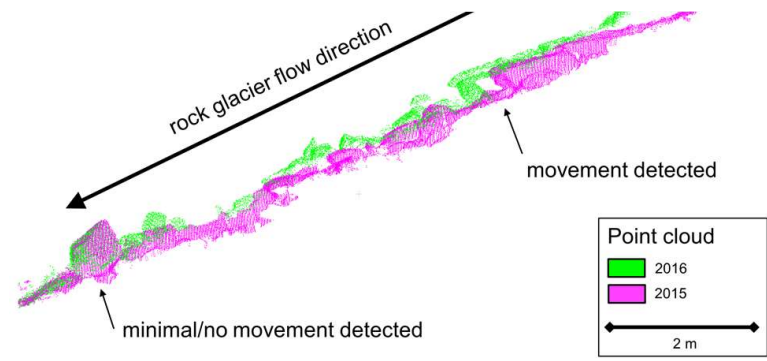

Figure 4. Differences in terrestrial laser scanning point clouds due to rock glacier movement between 2016 and 2017

Attention focused on the rock glacier "Äußeres Hochebenkar" (Nickus et al., 2013). The surface of the rock glacier presents highly dynamic changes (Fig. 4). A main part of the assignment is developing and applying methods to describe and analyse geomorphologic features and dynamics on the basis of point clouds acquired by the participants of the ISPRS summer school and datasets collected in previous years (cf. Rutzinger et al., 2016).

2.5.2 Assignment 4: Watching grass grow and hills slide: terrestrial laser scanning-based deformation monitoring. The processing chain of deformation monitoring has not lost its validity since it was proposed in the early years of the twentieth century. The steps conducted were network design and viewpoint planning to determine optimal viewpoints for observation, data acquisition (of at least two epochs), transformation of all epochs into a common and stable coordinate system, and deformation monitoring. 3D point clouds of a landslide located on the orographic right side between Zwieselstein and Obergurgl (Fig. 5a) were acquired with two terrestrial laser scanners from multiple positions. A long-range Riegl VZ-6000 and a Z+F phase-based laser scanner were used. The resulting point clouds 
were transformed into the same coordinate system as the reference point clouds acquired in 2016. Different filtering techniques for classifying ground and non-ground points were discussed and applied. Finally, topographical changes caused by the landslide were quantified based on the registered multitemporal data sets.

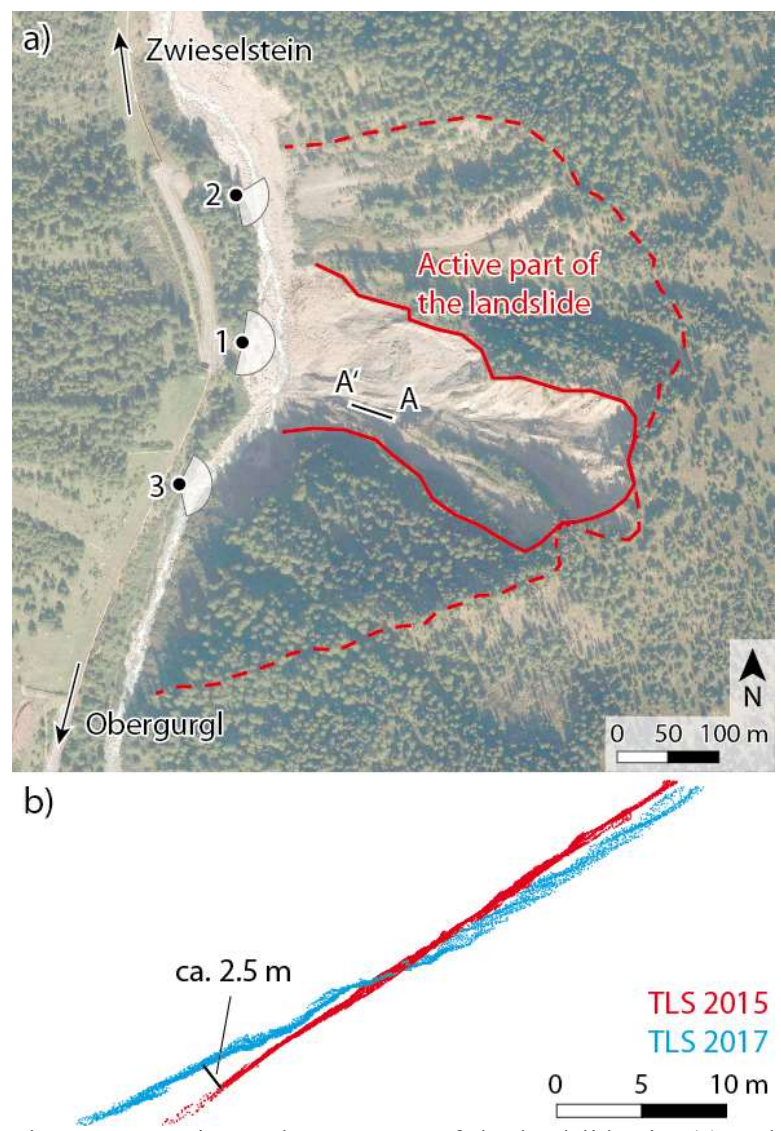

Figure 5. Location and TLS setup of the landslide site (a) and Profile A-A' (b) showing changes between the data acquisitions

2.5.3 Assignment 5: Classification and validation of $3 D$ point clouds with a data-rich set of descriptors. The study site consists of a rock face of $20 \times 3 \mathrm{~m}$ in size, with short and tall vegetation. The objective of the assignment was to extract a 3D point cloud from stereo images taken using a full-spectrum NIKON D80 camera; each scene was photographed with a pair of images, with (NIR) and without (FULL) a Hoya R72 cut filter. This modified user-grade camera allowed trainees to obtain six bands for each scene. The six bands were transformed to compensate for different exposure time and for the infrared absorption tail of the blue and green bands (Fredembach and Süsstrunk, 2008). The version of the software (Agisoft Photoscan Professional ${ }^{\circledR}$ ) allowed exporting a point cloud with three colours. The three bands containing most variability were extracted from each image pair. The block of images were then used to extract a point cloud in LAS format. Using CloudCompare (CloudCompare Development Team, 2017), additional descriptors (e.g. roughness) were extracted as well as subsets of points used for training and validation in supervised classification. Two classes were assigned to points using three machine learning algorithms, which were support vector machines, random forest, and bagging (Piragnolo et al., 2017; Pirotti et al., 2016). Accuracy was assessed with appropriate metrics, such as kappa index of agreement, precision and recall (Fig. 6).

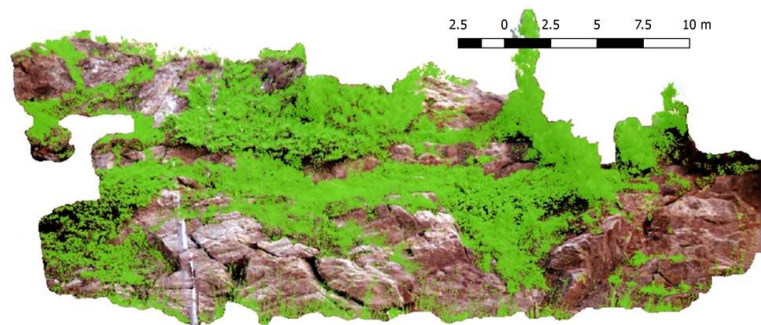

Figure 6. Points with vegetation class

Critical points of this assignment were: (i) small movements of elements in the scene: e.g. leaves and grass, due to wind, which caused imperfection in the overlap of image pairs - it can only be prevented by having a single sensor for RGBNIR; (ii) difficulty in determining additional descriptors: as a matter of fact only reflectance features gave optimal results in our case; (iii) small distortion between image pairs: minor movements of the camera and filter optics require a registration step using scale-invariant feature transform (SIFT) or similar methods (Chen et al., 2015) to solve this problem; (iv) processing time: training, classification and validation of millions of points require significant computation time, therefore the point cloud had to be resized to test all algorithms in time. Future versions of this assignment will apply the solutions to criticalities proposed above and provide a UV/NIR filter to have clean RGB images removing mixture from the infrared absorption tail.

2.5.4 Assignment 6: How the mountain river modifies the ground: A UAV application project. SfM and dense matching are two consolidated techniques for producing point clouds from images within a fully automatic technique (Eltner et al., 2016). A camera installed in the payload of a fixed-wing UAV allowed reconstructing the terrain topography of a large area in a mountain valley (namely, Rotmoos Valley), while a block of images captured with a ground-based camera was used for integrating vertical walls, e.g. the eroded riverbanks. Both data sets were georeferenced into the same mapping reference frame using GNSS/geodetic measurements of targets to be used as 3D ground control points (GCPs). UAV and ground-based photogrammetric blocks were independently processed to compute image orientation including camera calibration using the SfM function implemented in Agisoft Photoscan Professional ${ }^{\circledR}$ ver. 1.2.5. In the next stage, two distinct point clouds were obtained using the dense image matching function implemented in the same software package. Only at this stage were both point clouds merged by using GCPs to obtain a digital surface model of the entire study region. The DSM could be used for extracting geomorphological features, such as the current riverbed location. In addition, thanks to the availability of a DSM derived from a 2015 Summer School project (see Rutzinger et al., 2016), the comparison with 2017 DSM should have allowed highlighting any changes. In practice, because there was only partial overlap of the areas covered in these two projects (2015 and 2017), and there was a lack of permanent benchmarks to reestablish the same reference system, the comparison produced unsatisfactory results. This problem highlights the necessity of installing some permanent fixed benchmarks for making comparable future projects. The UAV flight, based on a fixedwing light unmanned aircraft, was repeated a second time during the same day by adopting a miniaturized multispectral sensor installed in the payload. The initial work plan was to register both data sets together, but the limited time prevented a full exploitation of multispectral images. However, data sets from the assignments will be made available for exploitation beyond the 
Summer School.

2.5.5 Assignment 7: Find the differences, the geo-version Change detection in multi-epoch point clouds in Alpine areas. Point clouds capture the 3D situation of a scene at a certain point in time. Multi-epoch point clouds provide information on changes between two data acquisition moments. In 2015 several datasets were collected from vegetation (Niederheiser et al. 2016), rocks and glaciers. The task in this assignment was to detect changes between 2015 and 2017 using multi-epoch point clouds from terrestrial imagery. In a $3 \mathrm{D}$ to $3 \mathrm{D}$ comparison step, the students first calculated pointwise differences, followed by a segmentation procedure that detects changed objects.

\section{RESULTS AND DISCUSSION}

\subsection{Participants}

A total of 38 participants were selected, from a wide range of countries (Figure7) and an even wider range of affiliations. An indicator of the success of this initiative is the fact that it attracted such a variety of affiliations of the applicants (see Tab. 2). The 38 participants are affiliated to 29 different institutions, were mainly younger than 30 years and PhD students (Fig. 8 and 9).

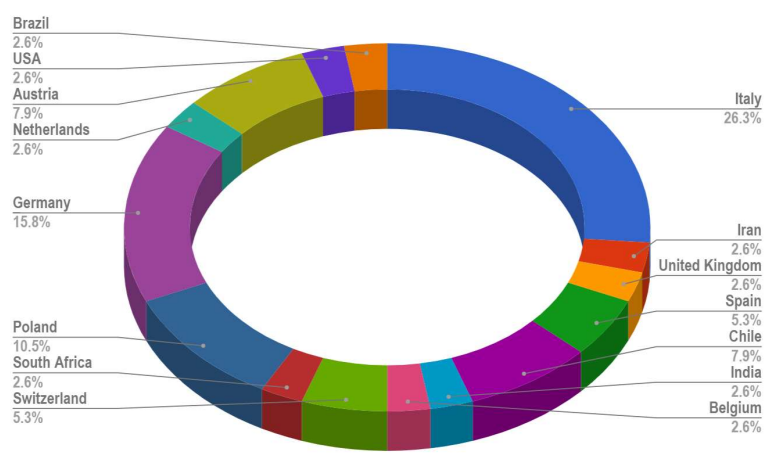

Figure 7. Distribution of the participants' countries

\begin{tabular}{ll}
\hline 1 & Delft University of Technology \\
2 & Friedrich-Alexander-University Erlangen-Nürnberg \\
3 & Friedrich-Schiller-University Jena \\
4 & ITC Enschede \\
5 & Jagiellonian University Cracow \\
6 & National Geospatial Information \\
7 & North-Eastern Hill University, Shilong \\
8 & Politecnico di Milano \\
9 & Polytechnic University of Bari \\
10 & Royal Haskoning DHV \\
11 & Snow and Avalanche Researh Centre Davos \\
12 & University of Chile \\
13 & University of Barcelona \\
14 & University of Bern \\
15 & University of Bonn \\
16 & University of Exeter \\
17 & Albert-Ludwigs-University of Freiburg \\
18 & University of Innsbruck \\
19 & University of Insubria \\
20 & University of Lausanne \\
21 & University of Padua \\
22 & University of Pavia \\
23 & University of Perugia \\
24 & University of Salzburg \\
25 & University of the Highlands and Islands, Perth, UK \\
26 & University of Zürich \\
27 & US Geological Survey Northern Rocky Mountain Science \\
28 & Centre \\
\hline
\end{tabular}

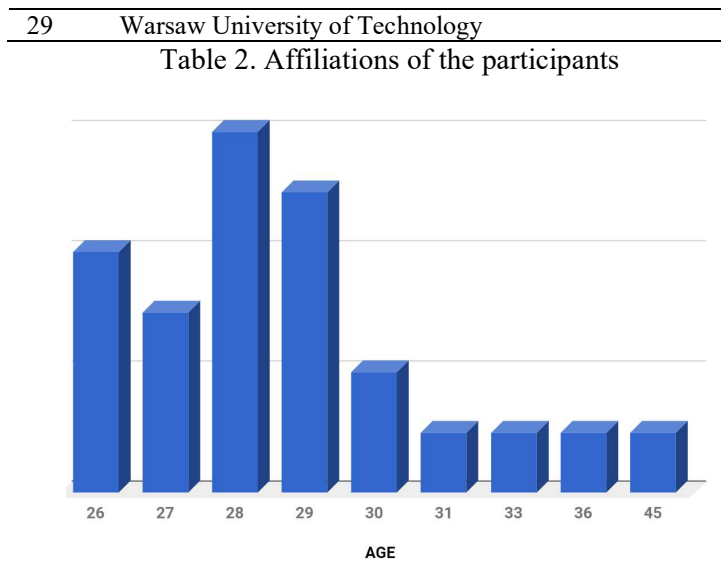

Figure 8. Age distribution of participants
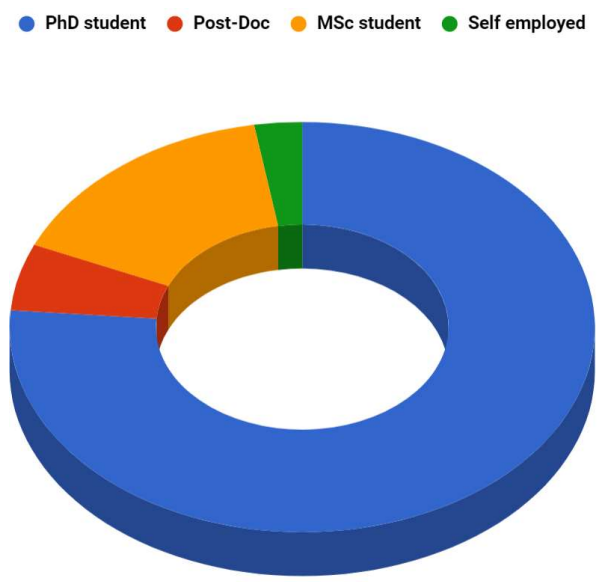

Figure 9. Distribution of participants' position

\subsection{Feedback from participants}

To assess the satisfaction of the participants with different aspects of the summer school, each of them was invited to complete an online form after the end of the summer school. The questionnaire had three sections, which were (i) related to organizational aspects, (ii) on how participants learned about the summer school and (iii) related to aspects of didactics and assignments. Table 3 lists the questions. Some questions required answers on an ordinal scale of 1 to 10 , with 10 the most favourable answer; these are marked with an asterisk in Table 3. Other answers had a nominal scale with predefined classes. 25 out of 38 scholars completed the questionnaire. To raise the turnout for upcoming summer schools, the participants could be encouraged to complete the form on the last day of the event.

\begin{tabular}{ll}
\hline N. & Organizational questions \\
$\mathbf{1}$ & Is the location of the summer school appropriate? \\
$\mathbf{2}$ & Are the facilities and services appropriate? (rooms, meals etc...) \\
$\mathbf{3}$ & $\begin{array}{l}\text { Please rate the overall schedule (time for talks, field work, data } \\
\text { processing, free time) }\end{array}$ \\
$\mathbf{A}$ & How did you learn about this summer school? \\
$\mathbf{B}$ & $\begin{array}{l}\text { If you were planning the next summer school, how would you } \\
\text { adjust the schedule? }\end{array}$ \\
& Assignment questions
\end{tabular}


C What assignment did you follow?

D What assignment was your first choice?

4 Was the topic and goal of the assignment clearly defined?

5 Was the schedule of time dedicated to assignment and fieldwork respected?

6 Was the ratio of lectures/field-work/demos ideal?

7 Did the assignment reflect what you expected in terms of contents?

8 Independently from your expectations, did the assignment add value to your knowledge-base?

9 Was the workload appropriate?

10 How do you rate the idea of writing the assignment report in the pre-defined ISPRS conference paper template?

11 Please provide a self-assessment of your motivation to polish your initial analyses beyond the summer school to finally produce a scientific publication

E For what reasons would you recommend your colleagues to attend this course unit? Please indicate what aspects you consider to be positive, satisfying or important.

F For what reasons would you not recommend your colleagues to attend this course unit? Please indicate what aspects are critical, unsatisfactory, unnecessary or disappointing

G Please add your suggestions for improvements.

H Add suggestions on how the interaction between participants and between participants and lecturers could be further improved.

Table 3. Questions in the feedback form. Values for column "N." are enumerated (1-11) for ordinal scale answers, or letters (A-D) for nominal scale and remaining $(\mathrm{E}-\mathrm{H})$ for free text answers

3.2.1 Questions 1-11: Possible statistics for ordinal scales can be median and other percentiles (Roberts, 1979; Stevens, 1946). These are reported in Figure 10 below.

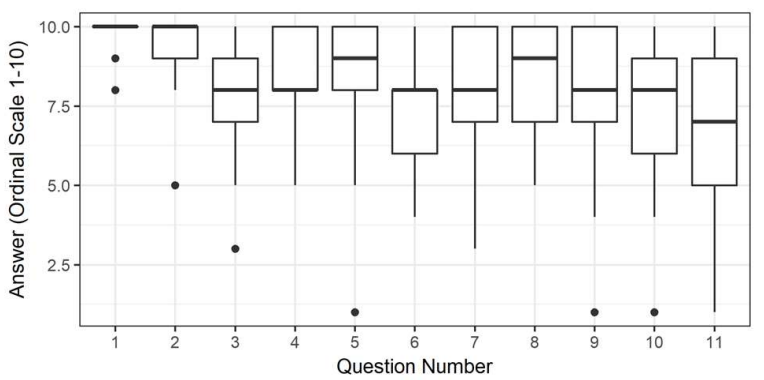

Figure 10. Answers to questions with ordinal-scale answers (10 high/good and 0 - low/bad) - question number as in Table 3. Boxes represent median and 25 th and 75 th percentile

The distribution of answers to the first three questions shows that location, services and schedule were highly appreciated by most. Question 3 received a couple of lower votes, related to requests for more time for data analysis. Question 5 also related to the time schedule had a few lower votes; see also discussion in the next section for more details on question B and Figure 10. It can be concluded that some assignments required more time so as not to be rushed. Questions 6 through 9 provide feedback on the overall satisfaction with assignments, and medians and quartile values are all quite above average. Question 9, on workload, had one outlier; one participant found it difficult to follow the assignment. The last question, 11, on the idea of further analysis of the work done in the summer school, triggered varied answers; most scholars were positive about this idea, but not all were enthusiastic about writing a research paper.
3.2.2 Questions A-D: Question A asked how participants learned about the summer school. Results are shown in Figure11. It is evident that most students proactively searched on the internet for this kind of event.

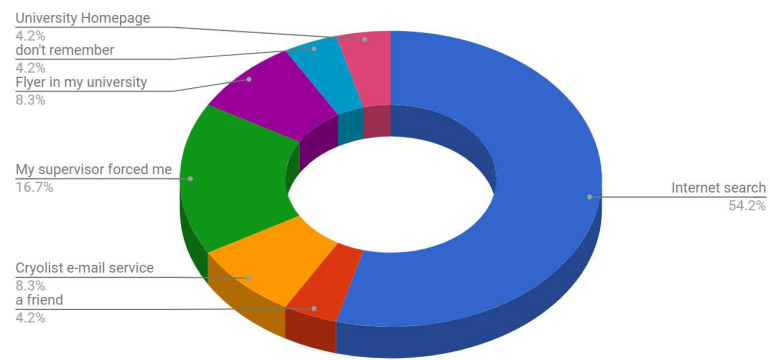

Figure 11. Break-down of how scholars learned about the summer school

The feedback on time assigned for different tasks (question B in Table 3 ) covered four aspects of the activities, lectures, field survey, assignment-related activity and free time. This free time is set aside for networking, self-learning and other activities to be decided freely by the participants. Results reported in Figure 12 show that most were fine with the allocated time schedule, except that many felt that more time would have been appropriate for field work and data analysis. This is probably due to the overall limited duration of the summer school.

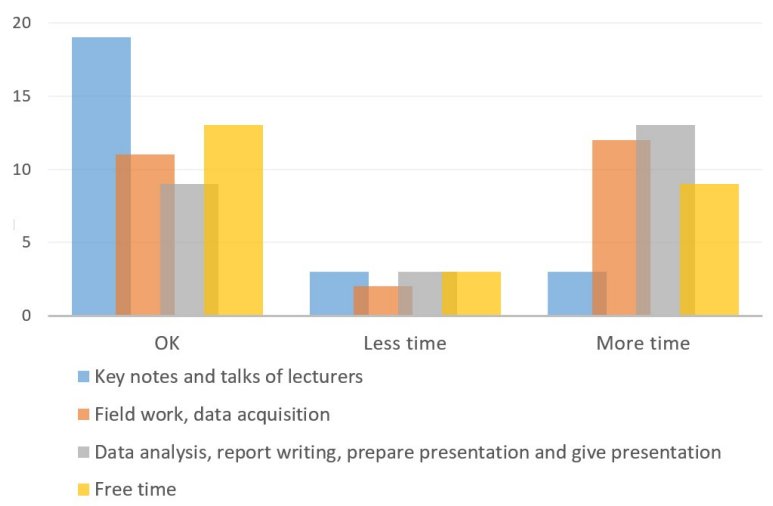

Figure 12. Participants' feedback on time schedule

For questions $\mathrm{C}$ and $\mathrm{D}$ on assignment selection, Figure 3 shows the number of people who chose each assignment. The distribution is again derived from the 25 responses. All assignments were chosen, but a few adjustments had to be made to distribute participants across assignments. Only four scholars out of 25 did not get their first choice assignment, but were reassigned to second or third choice. 


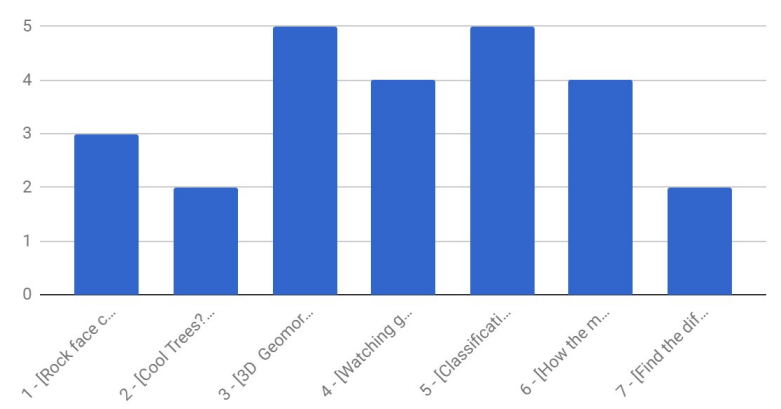

Figure 13. First choice assignments - see Table 1 for complete assignment title

3.2.3 Questions E-H: questions E through $\mathrm{H}$ had open answers and asked for positive or negative overall recommendations. Positive feedback related to the organization of hands-on practical surveys and analysis, robust scientific bases of lectures and assignments and a good mix of theoretical, practical and hands-on exercises. Negative responses were very few and mainly related to the time available to study the assignment's theoretical base in depth. In one case a participant wanted to follow more than one assignment. Participants also suggested extending the interaction activities between participants. There was interest in learning more about the professional and research background of participants and lecturers, for example, by an introductory round of short presentations by groups of participants of their field/subject/sensor/method. There were also calls for sending out the assignments prior to the summer school to allow scholars to prepare themselves by gathering information about the research topics in advance.

\section{CONCLUSIONS}

This article reported on the second edition of the "Innsbruck Summer School of Alpine Research" on "Close-range Sensing in Alpine Terrain" as organised in Obergurgl in July 2017. It is intended to hold this summer school biannually, which means that next event is planned for summer 2019. The feedback obtained by participants, for example, on scientific exchange will be used to improve the next edition. In addition, having established a tradition will enable participants and organizers to work increasingly with time series of the different phenomena in Alpine landscapes that can be observed in the valley of Obergurgl. At the same time, we feel that the link between close and near range sensing techniques as used in most assignments and satellite data, for example, from the Sentinel missions, should play a more prominent role in future editions. To share summer school knowledge with the rest of the world and to enable future participants to prepare themselves better, first tests have started with offering e-learning material. These improvements should allow young mountain researchers from all over the world to benefit directly from what the summer school has on offer.

\section{ACKNOWLEDGEMENTS}

The organizing committee of the summer school thanks all keynote speakers, all supportive administrative staff from the University of Innsbruck and staff at the University Centre Obergurgl for hosting the event. We also want to thank the sponsors: the Faculty of Geo- and Atmospheric Sciences and the Vice Rector for Research of the University of Innsbruck, University of Padova, Riegl Laser Measurement Systems GmbH, TU-Delft Climate Institute, Austrian Federal Office of Metrology and Surveying (Bundesamt für Eich- und Vermessungswesen,
BEV) and the Copernicus Academy. Additional thanks to the Austrian Research Centre for Forests (Bundesforschungszentrum für Wald, $\mathrm{BFW}$ ) for conducting the remotely piloted aircraft systems flight.
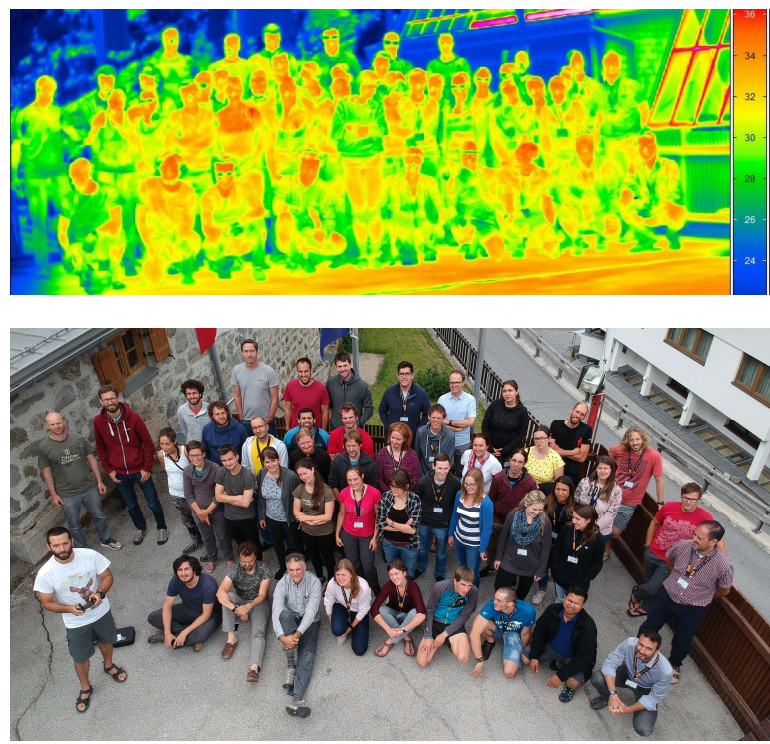

\section{REFERENCES}

ARO, 2018. Alpine Research Centre Obergurgl https://www.uibk.ac.at/afo/ (16 March 2018)

Bremer, M., Wichmann, V., Rutzinger, M., 2017. Calibration and Validation of a Detailed Architectural Canopy Model Reconstruction for the Simulation of Synthetic Hemispherical Images and Airborne LiDAR Data. Remote Sensing, 9(3), pp. 1$22 \mathrm{https} / / /$ doi.org/10.3390/rs9030220

Butler, D., 2014. Earth observation enters next phase. Nature, 508(7495), pp. 160-161 https://doi.org/10.1038/508160a

Chen, J., Dowman, I., Li, S., Li, Z., Madden, M., Mills, J., Paparoditis, N., Rottensteiner, F., Sester, M., Toth, C., Trinder, J., Heipke, C., 2015. Information from imagery: ISPRS scientific vision and research agenda. ISPRS Journal of Photogrammetry and Remote Sensing, 115, pp. 3-21 https://doi.org/10.1016/j.isprsjprs.2015.09.008

CloudCompare Development Team 2017. CloudCompare Software, Version $2.6 \mathrm{http}: / /$ www.cloudcompare.org/ (12 January 2018)

Eltner, A., Kaiser, A., Castillo, C., Rock, G., Neugirg, F. \& Abellán, A., 2016. Image-based surface reconstruction in geomorphometry - merits, limits and developments. Earth Surface Dynamics, 4, pp. 359-389 https://doi.org/10.5194/esurf4-359-2016

Fey, C. \& Wichmann, V., 2017. Long-range terrestrial laser scanning for geomorphological change detection in alpine terrain - handling uncertainties. Earth Surface Processes and $\begin{array}{llll}\text { Landforms, } & 42(5), & \text { pp. }\end{array}$ http://dx.doi.org/10.1002/esp.4022

Fredembach, C., Süsstrunk, S., 2008. Colouring the NearInfrared. Proceedings of the IS\&T 16th Color Imaging Conference, Portland, USA, pp. 176-182. 
Kraus, K., 2007. Photogrammetry: geometry from images and laser scans. Walter de Gruyter, Berlin, p. 476.

Mayr, A., Rutzinger, M., Bremer, M., Oude Elberink, S., Stumpf, F., Geitner, C., 2017. Object-based classification of terrestrial laser scanning point clouds for landslide monitoring. The Photogrammetric Record, 32(160), pp. 377-397 https://doi.org/10.1111/phor.12215

Micheletti, N., Tonini, M. \& Lane, S.N., 2017. Geomorphological activity at a rock glacier front detected with a 3D density-based clustering algorithm. Geomorphology, 278, pp. 287-297 https://doi.org/10.1016/j.geomorph.2016.11.016

Nickus, U., Abermann, J., Fischer, A., Krainer, K., Schneider, H., Span, N. \& Thies, H., 2013. Rock Glacier Äußeres Hochebenkar (Austria) - Recent results of a monitoring network. Zeitschrift für Gletscherkunde und Glazialgeologie, 47/48, pp. 43-62.

Niederheiser, R., Mokros, M., Lange, J., Petschko, H., Prasicek, G., Oude Elberink, S., 2016. Deriving 3D point clouds from terrestrial photographs: comparison of different sensors and software. In: International Archives of the Photogrammetry, Remote Sensing and Spatial Information Sciences, Prague, Czech Republic, Vol. XLI-B5, pp. 685-692 https://doi.org/10.5194/isprsarchives-XLI-B5-685-2016

Niederheiser, R., Rutzinger, M., Bremer, M. \& Wichmann, V., 2018. Dense image matching of terrestrial imagery for deriving high-resolution topographic properties of vegetation locations in alpine terrain. International Journal of Applied Earth Observation and Geoinformation, 66, pp. 146-158 https://doi.org/10.1016/j.jag.2017.11.011

Oude Elberink, S. \& Kemboi, B., 2014. User-assisted Object Detection by Segment Based Similarity Measures in Mobile Laser Scanner Data. International Archives of the Photogrammetry, Remote Sensing and Spatial Information Sciences, XL-3, 239-246, https://doi.org/10.5194/isprsarchivesXL-3-239-2014

Piragnolo, M., Masiero, A., Pirotti, F., 2017. Open source R for applying machine learning to RPAS remote sensing images. Open Geospatial Data, Software and Standards, 2(16), pp. 1-7 https://doi.org/10.1186/s40965-017-0033-4

Pirotti, F., Sunar, F., Piragnolo, M., 2016. Benchmark of Machine Learning Methods for Classification of a Sentinel-2 Image. In: International Archives of the Photogrammetry, Remote Sensing and Spatial Information Sciences, Prague, Czech Republic, Vol. XLI-B7, pp. 335-340 https://doi.org/10.5194/isprs-archives-XLI-B7-17-2016

Phan, V. H., Lindenbergh, R., Menenti, M., 2017. Assessing Orographic Variability in Glacial Thickness Changes at the Tibetan Plateau Using ICESat Laser Altimetry. Remote Sensing, 9(2), 160, pp. 1-19 https://doi.org/10.3390/rs9020160

Roberts, F.S., 1979. Measurement Theory with Applications to Decision Making, Utility, and the Social Sciences, Encyclopedia of Mathematics and its Applications. Cambridge University Press, Cambridge, p. 444.

Rutzinger, M., Höfle, B., Lindenbergh, R., Oude Elberink, S., Pirotti, F., Sailer, R., Scaioni, M., Stötter, J., Wujanz, D., 2016. Close-range sensing techniques in alpine terrain. ISPRS Annals of the Photogrammetry, Remote Sensing and Spatial Information Sciences, III-6, pp. 15-22 https://doi.org/10.5194/isprs-annalsIII-6-15-2016

Scaioni, M., Crippa, J., Longoni, L., Papini, M., \& Zanzi, L. (2017). Image-Based Reconstruction and Analysis of Dynamic Scenes in a Landslide Simulation Facility. ISPRS Annals of the Photogrammetry, Remote Sensing and Spatial Information Sciences, IV-5/W1, pp. 63-70 https://doi.org/10.5194/isprsannals-IV-5-W1-63-2017

Scaioni, M., Feng, T., Barazzetti, L., Previtali, M., \& Roncella, R., 2015. Image-based deformation measurement. Applied Geomatics, 7(2), pp. 75-90 https://doi.org/10.1007/s12518-0140152-x

Schwalbe, E., Koschitzki, R., Maas, H-G., 2016. Recognition of drainage tunnels during glacier lake outburst events from terrestrial image sequences. In: International Archives of the Photogrammetry, Remote Sensing and Spatial Information Sciences, XLI-B8, Prague, Czech Republic, pp. 537-543 https://doi.org/10.5194/isprs-archives-XLI-B8-537-2016

Shen, Y., Lindenbergh, R., \& Wang, J. (2016). Change Analysis in Structural Laser Scanning Point Clouds: The Baseline Method. Sensors, 17(1), 26 https://doi.org/10.3390/rs9020160

Stevens, S.S., 1946. On the Theory of Scales of Measurement. Science, 103, pp. https://doi.org/10.1126/science.103.2684.677

Van Westen, C. 2018. Risk mapping. Encyclopedia of Engineering Geology. Springer International Publishing, Cham, https://doi.org/10.1007/978-3-319-12127-7_240-1

Wujanz, D., Avian, M., Krueger, D., \& Neitzel, F., 2017. Identification of stable areas in unreferenced laser scans for automated geomorphometric monitoring. Earth Surface Dynamics Discussions, pp. 23 https://doi.org/10.5194/esurf2017-41

Wujanz, D., Krueger, D., Neitzel, F., 2016. Identification of stable areas in unreferenced laser scans for deformation measurement. The Photogrammetric Record, 31(155), pp. 261$280 \mathrm{https}: / /$ doi.org/10.1111/phor.12152 